\title{
PENGARUH BAURAN PEMASARAN TEHADAP MINAT BELI KONSUMEN DI MULIA ELEKTRONIK DI KOTA PADANG
}

\author{
Yessenia, Febsri Susanti \\ Sekolah Tinggi Ilmu Ekonomi KBP \\ febsrisusanti@akbpstie.ac.id \\ yesseniafirdaus@gmail.com
}

\begin{abstract}
This research aims to know the influence of marketing mix against the interest of the consumer to buy electronics at Noble in Padang city. The research method used was the type of quantitative research methods a descriptive research. Consumer buying interest $(Y)$ is variable, whereas the product strategy $(X 1)$, price $(X 2)$, promotion $(X 3)$, and $(X 4)$ is the free variable. The population used in this research are consumers whose data was taken from the Noble Electronics Research sample, as many as 100 people. Sample retrieval techniques used are the total sampling, namely the determination of the sample by taking the entire consumer population as respondents or sample. Data analysis technique used was multiple linear regression analysis. Sample retrieval techniques used are the total sampling, namely the determination of the sample by taking the entire consumer population as respondents or sample. Data analysis technique used was multiple linear regression analysis. From the results of research shown that variable product strategy (X 1) effect significantly to consumer buying interest $(Y)$ of 0.250 , variable price $(X 2)$ effect significantly to consumer buying interest $(Y)$ 0.223 , promotion of $(X 3)$ effect significantly to consumer buying interest $(Y)$ by 0.002 and places $(X \quad 4)$ effect significantly to consumer buying interest $(Y)$ of 0.079 means that quality of product, price, promotion and place equally influential interest significantly to buy consumers. The analysis used in this study includes test instruments, test validity, reliability test, test, test the classical assumptions of normality, test multikolinieritas, heterokedastisitas test, multiple linear regression analysis, hypothesis testing which includes the t-test, F-test. Therefore these limitations expected more noted for subsequent researchers.
\end{abstract}

Keywords: Conflicts Of Interest And Buy Marketing Mix

\section{PENDAHULUAN}

Semakin banyak permintaan masyarakat akan barang-barang elektronik, menyebabkan bisnis elektronik saat ini banyak ditemukan di berbagai tempat. Dari mulai bisnis pembuatan barang elektronik, toko-toko elektronik, bisnis jasa reparasi barang elektronik, sampai bisnis kredit elektronik banyak ditemukan di sekitar kita. Karena kebutuhan masyarakat akan barang elektronik juga semakin meningkat setiap tahun nya. Untuk itu dapat bertahan dan berkembang, pengelolapengelola bisnis penjualan alat elektronik dituntut untuk mampu menciptakan 
keunggulan-keunggulan bersaing atas harga. Kualitas produk merupakn salah satu factor penentu berikutnya, tingkat kepuasan konsumen setelah melakukan pembelian dan pemakaian terhadap suatu produk yang dijual. Seperti dalam penelitian yang dilakukan oleh Suci Dwi Puspita (2014) yang berjudul "Pengaruh Harga, Kualitas Produk, Dan Citra Merek Terhadap Keputusan Pembelian Yoghurt (Survey Pada Konsumen Yoghurt Youjell Pt. Insan Muda Berdikari)” dimana di dalamnya dibahas bahwa ada beberapa tahapan untuk mengelola kualitas suatu produk yaitu perencanaan kualitas, mengorganisasi untuk kualitas, pengarahan untuk kualitas, pengendalian untuk kualitas.

\section{1) Product (produk)}

Produk adalah segala sesuatu yang akan ditawarkan ke pasaran. Untuk dikonsumsi sehingga dapat memuaskan keinginan atau kebutuhan konsumen-konsumen tersebut Kotler (2001: 346).

\section{2) Price (harga)}

Menurut Kotler (2001: 439) harga adalah jumlah uang yang akan dibebankan atas suatu produk atau jasa, jumlah nilai yang dipertukarkan konsumen untuk manfaat yang dimiiliki dengan menggunakan produk atau menggunakan jasa.

\section{3) Kepercayaan (trust)}

Menurut Badan Pavlou (2002) mendefinisikan kepercayaan sebagai penilaian suatu hubungan seseorang dengan orang lainyang akan melakukan transaksi tertentu sesuai dengan harapan dalam sebuah lingkungan yang penuh ketidakpastian.

\section{4) Promotion (promosi)}

Promosi adalah merupakan alat yang digunakan perusahaan jasa untuk berkomunikasi dengan pasar sasaran. Dengan adanya promosi produsen atau distributor mengharapkan kenaikannya angka penjualan Payne (2000:189).

\section{Hipotesis}

H1 : Diduga harga berpengaruh signifikan dan positif terhadap keputusan pembelian elektronik di Mulia Elektronik

H2 :Diduga harga berpengaruh signifikan dan positif terhadap keputusan pembelian elektronik di Mulia Elektronik

H3 : Diduga harga berpengaruh signifikan dan positif terhadap keputusan pembelian elektronik di Mulia Elektronik

H4 : Diduga harga berpengaruh signifikan dan positif terhadap keputusan pembelian elektronik di Mulia Elektronik

\section{METODE PENELITIAN}

\section{Jenis Penelitian}

Jenis penelitian yang digunakan dalam penelitian ini adalah penelitian deskriptif kuantitatif. Teknik pengambilan sampel umumnya dilakukan secara random, pengumpulan data mengunakan instrument penelitian, analisis data bersifatkuantitatif / statistic dengan tujuan untuk menguji hipotesis yang ditetapkan. 


\section{Objek Penelitian}

Penelitian ini akan dilaksanakan di Mulia Elektronik Padang dengan mengumpulkan data - data penelitian dari jawaban respondenpen elitian.

\section{Populasi}

Populasi menurut Sugiyono (2012) adalah wilayah generalisasi yang terdiri atas objek atau subjek yang mempunyai kualitas dan karakteristik tertentu yang diterapkan oleh peneliti untuk dipelajari dan kemudian ditarik kesimpulan. Populasi dalam penelitian inia dalah konsumen yang berbelanja ke Mulia electronic. Dimana pengambilan data ini dilakukan pada bulan Januari sampai September tahun 2017 berjumlah 9392 orang.

\section{Jenis Dan Sumber Data}

Dalam kenyataannya menurut Sugiarto (2003) jenis data yang dikumpulkan terdiri dari beberapa data primer dan data sekunder. Data primer merupakan data yang didapat terdiri dari dari sumber pertama, baik individu atau perseorangan seperti hasil wawancara atau hasil pengisian kuesioner yang bisa dilakukan oleh peneliti. Teknik pengambilan data ini adalah data sekunder, karena dalam hal ini peneliti tidak secara langsung mengambil data sendiri tetapi meneliti.

\section{HASIL ANALISIS}

\section{A. Uji Validitas}

Suatu kuisioner dikatakan valid jika pernyataan pada kuesioner mampu mengungkapkan sesuatu yang akan diukur oleh kuesioner tersebut. Pengujian ini dilakukan dengan menggunakan Product momen Pearson Correlation yaitu dengan cara menghitung korelasi antar skor masing-masing butir pernyataan dengan total skor. 
Tabel 1

Hasil Uji Validitas

\begin{tabular}{|c|l|c|c|c|}
\hline Variabel & Pertanyaan & $\begin{array}{c}\text { Corrected item total } \\
\text { correlation }\end{array}$ & $\begin{array}{c}\text { Nilai } \\
\text { Kritis }\end{array}$ & Keterangan \\
\hline $\mathbf{X}_{\mathbf{1}}$ & Pertanyaan 1 & 0,634 & 0,30 & Valid \\
\hline & Pertanyaan 2 & 0,487 & 0,30 & Valid \\
\hline & Pertanyaan 3 & 0,524 & 0,30 & Valid \\
\hline & Pertanyaan 4 & 0,556 & 0,30 & Valid \\
\hline $\mathbf{X}_{\mathbf{2}}$ & Pertanyaan 1 & 0,603 & 0,30 & Valid \\
\hline & Pertanyaan 2 & 0,341 & 0,30 & Valid \\
\hline & Pertanyaan 3 & 0,316 & 0,30 & Valid \\
\hline & Pertanyaan 4 & 0,654 & 0,30 & Valid \\
\hline & Pertanyaan 5 & 0,575 & 0,30 & Valid \\
\hline $\mathbf{X}_{\mathbf{3}}$ & Pertanyaan 1 & 0,792 & 0,30 & Valid \\
\hline & Pertanyaan 2 & 0,445 & 0,30 & Valid \\
\hline & Pertanyaan 3 & 0,331 & 0,30 & Valid \\
\hline & Pertanyaan 4 & 0,600 & 0,30 & Valid \\
\hline & Pertanyaan 5 & 0,489 & 0,30 & Valid \\
\hline $\mathbf{X}_{\mathbf{4}}$ & Pertanyaan 1 & 0,550 & 0,30 & Valid \\
\hline & Pertanyaan 2 & 0,542 & 0,30 & Valid \\
\hline & Pertanyaan 3 & 0,403 & 0,30 & Valid \\
\hline & Pertanyaan 4 & 0,529 & 0,30 & Valid \\
\hline & Pertanyaan 5 & 0,358 & 0,30 & Valid \\
\hline $\mathbf{Y}$ & Pertanyaan 1 & 0,610 & 0,30 & Valid \\
\hline & Pertanyaan 2 & 0,347 & 0,30 & Valid \\
\hline & Pertanyaan 3 & 0,664 & 0,30 & Valid \\
\hline & Pertanyaan 4 & 0,531 & 0,30 & Valid \\
\hline & Pertanyaan 5 & 0,342 & 0,30 & Valid \\
\hline & Pertanyaan 6 & 0,662 & 0,30 & Valid \\
\hline & Pertanyaan 7 & 0,653 & 0,30 & Valid \\
\hline
\end{tabular}

Sumber : data diolah, 2018

\section{Uji Reabilitas}

Uji reliabilitas yaitu dilakukan untuk mengukur suatu angket yang merupakan suatu indikator dari variabel. Indikator untuk uji reliabilitas adalah Cronbach's Alpha, dimana apabila nilai Cronbach's Alpha> 0,6 maka instrumen yang digunakan reliable. Pada penelitian ini, uji reliabilitas yang dilakukan pada 100 responden.

Tabel 2

Hasil Uji Reliabilitas

\begin{tabular}{|c|c|c|c|}
\hline Variabel & Crobac's Alpha & R Tabel & keterangan \\
\hline $\mathrm{X}_{\mathrm{I}}$ & 0,898 & 0,60 & Reliabel \\
\hline $\mathrm{X}_{\mathrm{II}}$ & 0,860 & 0,60 & Reliabel \\
\hline $\mathrm{X}_{\mathrm{III}}$ & 0,851 & 0,60 & Reliabel \\
\hline $\mathrm{X}_{\mathrm{IV}}$ & 0,829 & 0,60 & Reliabel \\
\hline $\mathrm{Y}$ & 0,886 & 0,60 & Reliabel \\
\hline
\end{tabular}

Sumber : data diolah, 2018 


\section{Uji Regresi Berganda}

Uji regresi linear berganda digunakan untuk melihat pengaruh semua variabel independen terhadap variabel dependen. Berdasarkan data penelitian yangdikumpulkan baik dan untuk variable terikat $(\mathrm{Y})$ maupun variabelbebas $\left(\mathrm{X}_{1}, \mathrm{X}_{2}, \mathrm{X}_{3}, \mathrm{X}_{4}\right)$ yang diolah dengan menggunakan dan bantuan program SPSS version 16.0for windows.

Tabel 3

Hasil Uji Regresi Berganda

Coefficients $^{\mathrm{a}}$

\begin{tabular}{|c|c|c|c|c|c|}
\hline \multirow[b]{2}{*}{ Model } & \multicolumn{2}{|c|}{$\begin{array}{c}\text { Unstandardized } \\
\text { Coefficients }\end{array}$} & \multirow{2}{*}{$\begin{array}{c}\text { Standardized } \\
\text { Coefficients }\end{array}$} & \multirow[b]{2}{*}{$\mathrm{t}$} & \multirow[b]{2}{*}{ Sig. } \\
\hline & B & Std. Error & & & \\
\hline 1 (Constant) & 1.846 & 1.932 & & 1.009 & .003 \\
\hline $\mathrm{X} 1$ & .755 & .137 & .178 & 1.802 & .004 \\
\hline $\mathrm{X} 2$ & .768 & .134 & .166 & 1.552 & .001 \\
\hline $\mathrm{X} 3$ & .765 & .079 & .003 & 4.000 & .002 \\
\hline $\mathrm{X} 4$ & .758 & .138 & .057 & 4.049 & .001 \\
\hline
\end{tabular}

a. Dependent Variable:

Y

Pada tabel korelasi menunjukan suatu hubungan.Korelasi antara hubungan Pengaruh Bauran Pemasaran Terhadap Minat BeliKonsumen. Dari tabel diatas dapat diperoleh persamaan regresi linear sebagai berikut :

$$
Y=1.846+.755 X_{1}+.768 X_{2}+.765 X_{3}+.758 X_{4}
$$

1. Jika di asumsikan $X_{1}, X_{2}, X_{3}, X_{4}$ adalah nol maka minat beli di mulia elektronick adalah constan 1.846

2. Jika Produk di asumsikan satu satuan maka akan miningkatkan minat beli sebasar 0,755

3. Jika Price di asumsikan satu satuan maka akan miningkatkan minat beli sebasar 0,768

4. Jika Promosi di asumsikan satu satuan maka akan miningkatkan minat beli sebasar 0,765

5. Jika Place di asumsikan satu satuan maka akan miningkatkan minat beli sebasar 0,758 
Uji Parsial T

Tabel 4

Hasil Uji t

Coefficients $^{\mathrm{a}}$

\begin{tabular}{|c|c|c|c|c|c|}
\hline \multirow[b]{2}{*}{ Model } & \multicolumn{2}{|c|}{$\begin{array}{c}\text { Unstandardized } \\
\text { Coefficients } \\
\end{array}$} & \multirow{2}{*}{$\begin{array}{c}\begin{array}{c}\text { Standardized } \\
\text { Coefficients }\end{array} \\
\text { Beta }\end{array}$} & \multirow[b]{2}{*}{$\mathrm{t}$} & \multirow[b]{2}{*}{ Sig. } \\
\hline & B & Std. Error & & & \\
\hline 1 (Constant) & 1.846 & 1.932 & & 1.009 & .003 \\
\hline $\mathrm{X} 1$ & .755 & .137 & .178 & 1.802 & .004 \\
\hline $\mathrm{X} 2$ & .768 & .134 & .166 & 1.552 & .001 \\
\hline X3 & .765 & .079 & .003 & 4.000 & .002 \\
\hline $\mathrm{X} 4$ & .758 & .138 & .057 & 4.049 & .001 \\
\hline
\end{tabular}

a. Dependent Variable: Y

Berdasarkan tabel 4.14. Maka Pengaruh Bauran Pemasaran Terhadap Minat BeliKonsumenadalah sebagai berikut :

a. $\mathrm{X} 1=$ berdasarkan hasil pengolahan data dapat dilihat bahwa nilai t-hitung (1.802) dan nilai signifikansinya 0,004. Hal ini berarti signifikansi lebih kecil dari 0,05. Hal ini menunjukan ada pengaruh yang positif dan signifikan antara variabel X1 terhadap Y. Jadi hipotesisnya H0 diterima Ha ditolak

b. $\mathrm{X} 2=$ berdasarkan hasil pengolahan data dapat dilihat bahwa nilai t-hitung (1.552) dan nilai signifikansinya 0,001 . Hal ini berarti signifikansi lebih kecil dari 0,05 . Hal ini ada pengaruh yang positif dan tidak signifikan antara variabel X2 terhadap Y. Jadi hipotesisnya H0 diterima Ha ditolak

c. $\mathrm{X} 3=$ berdasarkan hasil pengolahan data dapat dilihat bahwa nilai t-hitung (4.000) dan nilai signifikansinya 0,002. Hal ini berarti signifikansi lebih kecil dari 0,05. Hal ini menunjukan ada pengaruh yang positif dan signifikan antara variabel X3 terhadap Y. Jadi hipotesisnya H0 diterima Ha ditolak

d. $\mathrm{X} 4=$ berdasarkan hasil pengolahan data dapat dilihat bahwa nilai t-hitung (4.049) dan nilai signifikansinya 0,001. Hal ini berarti signifikansi lebih kecil dari 0,05. Hal ini menunjukan ada pengaruh yang positif dan signifikan antara variabel X4 terhadap Y. Jadi hipotesisnya H0 diterima Ha ditolak

\section{SIMPULAN}

Penelitian ini meneliti Pengaruh Bauran Pemasaran Terhadap Minat Beli Konsumen Di Mulia Electronick. Penelitian ini telah dilakukan dengan menyebarkan kusioner 100 orang responden yang merupakan pengunjung di mulia elecktronik. Data pada penelitian ini diolah menggunakan SPSS 16.00 for windows.

Dari hasil pengujian dengan sofwereSPSS16.00 for windows disimpulkan bahwa deskripsi dari jawaban para responden terhadap variabel Bauran Pemasaran Terhadap Minat Beli Konsumen. 
Berdasarkan hasil analisis koefisien regresi berganda Bauran Pemasaran berpengaruh positif terhadap Minat Beli Konsumen. Dimana persamaan regresi berganda adalah

$\mathrm{Y}=1.846+.755 \mathrm{X}_{1}+.768 \mathrm{X}_{2}+.765 \mathrm{X}_{3}+.758 \mathrm{X}_{4}$

Hal ini menunjukan ada pengaruh positif dan signifikan. Jadi hipotesisnya $\mathrm{HO}$ diterima Ha ditolak (ada pengaruh yang signifikan antara masing-masing variable independen terhadap variable dependen)

\section{DAFTAR PUSTAKA}

Adrian Payne, 2000.”Service Marketing Pemasaran Jasa”, Andi Yogyakarta.

Andika, A., \& Susanti, F. (2018). Pengaruh Marketing Mix Terhadap Keputusan Pembelian Parfum di Azzwars Parfum Lubeg Padang. https://doi.org/10.31227/osf.io/upgc3

Arikunto, Suharsimi, 2002. Prosedur Penelitian Suatu Pendekatan Praktek. Jakarta. PT. Rineka Cipta.

Arikunto (2010). Prosedur Penelitian: Suatu Pendekatan Praktek. Jakarta: Rineka Cipta.

Aziz, N. (2019). Pengaruh Strategi Promosi Terhadap Keputusan Pembelian Yang Dimediasi Oleh Minat Beli Pada Konsumen Restoran KFC Cabang Khatib Sulaiman Padang. https://doi.org/10.17605/OSF.IO/V92TS

Aziz, N. (2019). Analisis Pengaruh Kualitas Produk, Harga, Promosi Terhadap Keputusan Pembelian Air Minum Dalam Kemasan (AMDK) Merek Aicos Produksi Pt. Bumi Sarimas Indonesia. https://doi.org/10.17605/OSF.IO/8XKYB

Ghozali, Imam. 2005. Aplikasi Analisis Multivariate dengan SPSS. Semarang: Badan Penerbit UNDIP.

Ghozali, Imam. 2011. "Aplikasi Analisis Multivariate Dengan Program SPSS". Semarang: Badan Penerbit Universitas Diponegoro.

Hermawan Kartajaya. 2006. Hermawan Kartajaya on Segmentation Seri 9 Elemen Marketing. Bandung: PT. Mizan Pustaka.

Hidayati, R. R., \& Marlius, D. (2018). Aktivitas Promosi Dalam Meningkatkan Dana Pihak Ketiga Pada PT. Bank Perkreditan Rakyat (BPR) Batang Kapas Pesisir Selatan. https://doi.org/10.31227/osf.io/8dgqn

Kotler, Philip. (2001). Manajemen Pemasaran: Analisis, Perencanaan, Implementasi, dan Kontrol. Jakarta : PT. Prehallindo.

Kotler, Philip dan Gary Armstrong, 2001, Prinsip-prinsip Pemasaran, Jilid 1, Edisi Kedelapan, Jakarta, Erlangga. 
Marlius, D. (2017). Keputusan Pembelian Berdasarkan Faktor Psikologis Dan Bauran Pemasaran Pada PT. Intercom Mobilindo Padang. Jurnal Pundi. Volume 1. No. 1. Hal. 57-66. https://doi.org/10.31575/jp.v1i1.9

Marlius, D. (2016). Pengaruh Bauran Pemasaran Jasa Terhadap Minat Nasabah Dalam Menabung Pada Bank Nagari Cabang Muaralabuh. https://doi.org/10.31227/osf.io/vdqgx

Mayliza, R. (2019). Pengaruh Kesadaran Merek, Asosiasi Merek Dan Perception Of Quality Terhadap Keputusan Pembelian Hospital Bed Merek Paramout Di PT. Aga Medika Utama Padang (Studi Kasus Rumah Sakit Umum Kota Padang). https://doi.org/10.17605/OSF.IO/VYQ4E

Mayliza, R. (2019). Analisis Keputusan Pembelian Ulang Axis Ditinjau Dari Bauran Pemasaran Kasus Di Kota Padang. https://doi.org/10.31219/osf.io/e7xhy

Priyanti,Y. Susanti, F. Aziz, N. (2017). Minat Beli Konsumen Toko Sepatu Bata Dipasar Raya Padang Dilihat Dari Sikap Dan Iklan. Jurnal Pundi, Vol. 01, No. 02

Ridwan (2011). Dasar-dasar Statistika. Bandung: Alfabeta.

Sugiyono ( 2012). Metode Penelitian Kuantitatif Kualitatif dan R\&D. Bandung: Alfabeta.

Sugiarto (2003). Teknik Sampling, Gramedia, Jakarta

Sugiyono. (2005). Memahami Penelitian Kualitatif. Bandung: ALFABET.

Susanti, F. (2015). Pengaruh Bauran Promosi Terhadap Keputusan Klien Dalam Memilih Radio Carano Sebagai Media Promosi Iklan. https://doi.org/10.31227/osf.io/b9ws7

Susanti, F. (2014). Pengaruh Tarif Iklan Terhadap Pendapatan Pada PT. Radio Swara Carano Batirai Indah Batusangkar. https://doi.org/10.31227/osf.io/dy863 